\author{
ANETA R. BORKOWSKA \\ EWA ZAWADZKA \\ Maria Curie-Skłodowska University, Lublin
}

\title{
VERBAL WORKING MEMORY IN ADHD CHILDREN
}

\begin{abstract}
According to neuropsychological models of ADHD, deficits of working memory are regarded as an essential cognitive phenotype for the disorder (Barkley, 1997; Castellanos \& Tannock, 2002; Martinussen \& Tannock, 2006). The primary goal of the present study was to compare the functioning of the phonological loop and the central executive system in the situation of manipulation of verbal material in children with ADHD (inattentive and mixed subtypes) and without ADHD. 132 children 9-11 years old were examined. Results revealed worse performance of tasks in ADHD children than in healthy children. It may be considered not as a result of difficulties in the performance of operations on verbal material (central executive system) but as a consequence of difficulties in the material maintained in the phonological loop of verbal working memory. There were no differences between mixed ADHD and inattentive ADHD groups.

Key words: verbal working memory, WM neuronal basis, ADHD children, neuropsychological models of ADHD, central executive system
\end{abstract}

\section{Working memory model}

Working memory is understood as a complex cognitive system for short-term storage and management of information (Baddeley, 2003; Binder, 2001; Szatkowska, 2005). The activity of different parts of the system is dependent on the kind of processed information (verbal versus spatial).

The most influential contemporary model of working memory was developed by Alan Baddeley and Graham Hitch. In its original form the model comprised three discrete sub-components (the central executive, articulatory loop and visuospatial scratch pad), which represent different types of information processing

Address for correspondence: Address for correspondence: Aneta R. Borkowska, Departament of Clinical Psychology and Neuropsychology, Institute of Psychology, Maria Curie-Skłodowska University, pl. Litewski 5, 20-080 Lublin, Poland. E-mail: aneta.borkowska@autograf.pl 
(passive storage, rehearsal of one- or multimodal information, operation of information). The current version of the model (Baddeley, 2003; Binder, 2001; Szatkowska, 2005) outlines four main components: central executive, phonological loop (containing the phonological store and an articulatory rehearsal component), visuospatial sketchpad (composed of visual cache and inner scribe) and episodic buffer. The main task of the phonological loop and the visuospatial sketchpad is temporary storage of verbal and visuospatial information, respectively. The episodic buffer has the task of storing complex and multimodal information. The central executive performs several functions: $1 /$ it processes information stored in buffers, $2 /$ it coordinates the work of memory buffers and allocates memory resources, especially when more than one task must be done at the same time, and $3 /$ it controls information processing.

An important direction of research into working memory has been the problem of its neuronal basis. Brain imaging studies have revealed that brain areas activated during working memory tasks are scattered over a large part of the cortex. Some studies (Van Rooy et al., 2001; Westerberg et al., 2001; Baddeley, 2003) showed activity of the prefrontal and parietal networks which occurred in different regions depending on the nature of the information processed. During phonological tasks (i.e. memorizing word lists), strong activity was observed in the anteromedial frontal gyrus and the inferior parietal lobe (Baddeley, 2003; Vallar \& Papagno, 2002; Smith \& Jonides, 1997; Jodzio, 2008). Performance on visual tasks (i.e. storage of information about shapes and colours of letters) activated the posterior prefrontal regions in medial and superior frontal gyrus and in the superior parietal lobe (Van Rooy et al., 2001; Smith \& Jonides, 1997; Binder, 2001; Baddeley, 2003). However, task dependent differences in brain activity were limited to the occipital region for the spatial memory tasks, to the inferior temporal region for object memory tasks, and to Broca's area for the verbal memory tasks. Brain imaging studies show a tendency for verbal tasks to recruit more left-hemisphere areas and for spatial working memory to activate more right-hemisphere regions.

Brain imaging studies also provide evidence of the dissociation between storage and rehearsal aspects of working memory. The left posterior parietal cortex is responsible for storage of verbal information but left frontal regions (Broca's area, the premotor cortex and the additional motor cortex) are involved in rehearsal (Baddeley, 2003; Binder, 2001). Storage of spatial information in working memory activates the right posterior parietal regions but rehearsal recruits the right premotor cortex (Van Rooy et al., 2001; Baddeley, 2003). The dorsolateral prefrontal cortex is evoked by the process of manipulating information in working memory (Smith \& Jonides, 1997; Szatkowska, 2005). The dorsolateral prefrontal cortex is activated in executive function tasks when monitoring information stored in working memory, shifting between tasks, applying rules maintained in working memory, and when planning a series of movements is involved (Baddeley, 2003; Binder, 2001; Szatkowska, 2005; Andres, 2003). 


\section{Working memory in ADHD}

According to neuropsychological models of ADHD, deficits of working memory are regarded as an essential cognitive phenotype for the disorder (Barkley, 1997; Castellanos \& Tannock, 2002; Martinussen \& Tannock, 2006). Nevertheless, the results of empirical assessments of working memory in ADHD children are inconsistent. One explanation for this variability in the studies is the use of disparate sampling criteria with or without controlling for comorbidity between ADHD and dyslexia or other language learning disorders. Consideration of this variable sampling is important because some results have suggested that in children with isolated language disorders (without ADHD) deficits were observed in verbal and spatial storage and in the functioning of the central executive component of working memory.

Some sparse reported findings suggest that ADHD children (with or without language impairments) as well as children with isolated language disorders, exhibit weakness in all aspects of working memory (Wu et al., 2006). Nevertheless, children with language difficulties (with or without ADHD) exhibit more severe deficits in verbal storage. This suggests that deficits of verbal storage are specifically associated with language disorders and not with ADHD. It was also found that deficits in the executive verbal or spatial component were associated with symptoms of inattention but not with symptoms of impulsivity-hyperactivity. However, there were discrete differences in the results dependent on whether or not IQ was controlled for (Cohen et al., 2000; Wu et al., 2002; Martinussen \& Tannock, 2006).

According to Barkley's model, executive function impairments (Barkley, 1997) and deficits in the central executive component of working memory are associated with ADHD impulsive-hyperactive and combined subtypes, but not with the ADHD inattentive subtype. There is little research investigating ADHD subtype differences across multiple components of working memory. Existing findings suggest that deficits in the central executive components of working memory are more strongly associated with inattention than with the hyperactivity-impulsivity dimension, what is inconsistent with Barkley's model (Wu et al., 2006; Brocki et al., 2007).

Martinussen and Tannock (2006) examined differences in the components of working memory functioning among ADHD with and without comorbid language learning disorders, and relations between working memory impairments and symptoms of inattention and hyperactivity /impulsivity. Four groups of children participated: isolated ADHD, isolated language disorder, comorbid ADHD and language disorder and control. ADHD children with or without comorbid language learning disorder exhibited deficits in visual-spatial storage and in visual-spatial and verbal central executive. Children with language learning disorder, regardless of comorbidity with ADHD, exhibited impairments in verbal and visual-spa- 
Table 1. Descriptive characteristics of the samples

\begin{tabular}{|c|c|c|c|c|c|c|c|}
\hline \multirow[t]{2}{*}{ Variable } & \multicolumn{2}{|c|}{$\begin{array}{l}\text { Mixed ADHD } \\
\quad(\mathrm{N}=64)\end{array}$} & \multicolumn{2}{|c|}{$\begin{array}{l}\text { Inattentive ADHD } \\
\qquad(\mathrm{N}=21)\end{array}$} & \multicolumn{2}{|c|}{$\begin{array}{r}\text { Control } \\
(\mathrm{N}=47)\end{array}$} & \multirow[t]{2}{*}{ Pairwise comparison } \\
\hline & M & SD & M & SD & $\mathrm{M}$ & SD & \\
\hline nonths) & 136.14 & 10.86 & 33 & .17 & 138.51 & 9.66 & \multirow{9}{*}{$\begin{array}{l}\text { mixed ADHD }= \\
\text { inattentive ADHD = control } \\
\text { mixed ADHD }= \\
\text { inattentive ADHD = control } \\
\text { mixed ADHD }> \\
\text { inattentive ADHD }>\text { control } \\
\text { mixed ADHD }> \\
\text { inattentive ADHD }>\text { control } \\
\text { mixed ADHD }> \\
\text { inattentive ADHD }>\text { control } \\
\text { mixed ADHD }> \\
\text { inattentive ADHD }>\text { control } \\
\text { mixed ADHD }> \\
\text { inattentive ADHD }>\text { control } \\
\text { mixed ADHD }= \\
\text { inattentive ADHD }>\text { control } \\
\text { mixed ADHD }> \\
\text { inattentive ADHD }>\text { control }\end{array}$} \\
\hline all IQ & 110.35 & 12.65 & 108.31 & 13.92 & 112.78 & 11.33 & \\
\hline LP & 41.03 & 6.68 & 27.40 & 7.41 & 11.76 & 5.81 & \\
\hline $\mathrm{PN}$ & 21.85 & 3.83 & 19.46 & 3.39 & 7.16 & 4.18 & \\
\hline PI & 19.20 & 4.10 & 9.66 & 3.63 & 4.60 & 2.27 & \\
\hline KN & 8.03 & 1.34 & 7.20 & 1.26 & 1.40 & 1.97 & \\
\hline KI & 7.09 & 1.43 & 2.73 & 1.57 & 0.64 & 1.03 & \\
\hline $\begin{array}{l}\text { OWA Conners } \\
\text { or Teachers }\end{array}$ & 16.22 & 5.23 & 12.66 & 5.57 & 7.12 & 5.94 & \\
\hline $\begin{array}{l}\text { IOWA Conners } \\
\text { for Parents }\end{array}$ & 19.24 & 4.10 & 14.00 & 4.79 & 8.32 & 5.03 & \\
\hline \multicolumn{8}{|l|}{ CBCL } \\
\hline $\begin{array}{l}\text { Anxious- } \\
\text { lepressed }\end{array}$ & 1 & 5.13 & 5 & 5.43 & 5.57 & 3.52 & \multirow{5}{*}{$\begin{array}{l}\text { mixed ADHD }> \\
\text { inattentive ADHD = control } \\
\text { mixed ADHD }> \\
\text { inattentive ADHD }>\text { control } \\
\text { mixed ADHD }> \\
\text { inattentive ADHD }>\text { control } \\
\text { mixed ADHD }= \\
\text { inattentive ADHD }>\text { control } \\
\text { mixed ADHD }> \\
\text { inattentive ADHD }>\text { control }\end{array}$} \\
\hline $\begin{array}{l}\text { ttention } \\
\text { roblems }\end{array}$ & 13.78 & 4.56 & 11.25 & 3.91 & 6.27 & 3.62 & \\
\hline $\begin{array}{l}\text { Aggressive } \\
\text { ehavior }\end{array}$ & 20.96 & 7.68 & 17.10 & 9.02 & 8.63 & 5.41 & \\
\hline $\begin{array}{l}\text { Delinquent } \\
\text { behavior }\end{array}$ & 5.93 & 4.12 & 6.25 & 3.14 & 2.96 & 3.16 & \\
\hline Total score & 67.05 & 23.01 & 53 & 28.24 & 31.78 & 18.96 & \\
\hline \multicolumn{8}{|l|}{ TRF } \\
\hline $\begin{array}{l}\text { Anxious- } \\
\text { lepressed }\end{array}$ & 3 & 5.01 & 7. & 4.79 & 4.21 & 4.29 & \multirow{5}{*}{$\begin{array}{l}\text { mixed } \mathrm{ADHD}> \\
\text { inattentive } \mathrm{ADHD}=\text { control } \\
\text { mixed } \mathrm{ADHD}> \\
\text { inattentive } \mathrm{ADHD}>\text { control } \\
\text { mixed } \mathrm{ADHD}> \\
\text { inattentive } \mathrm{ADHD}>\text { control } \\
\text { mixed } \mathrm{ADHD}= \\
\text { inattentive } \mathrm{ADHD}>\text { control } \\
\text { mixed ADHD }> \\
\text { inattentive ADHD }>\text { control }\end{array}$} \\
\hline $\begin{array}{l}\text { Attention } \\
\text { roblems }\end{array}$ & 22.73 & 7.69 & 16.25 & 5.95 & 7.60 & 6.21 & \\
\hline $\begin{array}{l}\text { Aggressive } \\
\text { behavior }\end{array}$ & 22.87 & 9.26 & 16.90 & 8.18 & 8.30 & 8.55 & \\
\hline $\begin{array}{l}\text { Delinquent } \\
\text { behavior }\end{array}$ & 7.79 & 3.48 & 6.05 & 2.41 & 3.09 & 3.86 & \\
\hline Total score & 79.25 & 25.52 & 57.15 & 22.08 & 29.12 & 28.06 & \\
\hline
\end{tabular}

FULL IQ in WISC-R; OLP - total scores on ADHD Rating Scale; LPN - scores on the ADHD Rating Scale inattention sub-scale; LPI - scores on the ADHD Rating Scale hyperactivity-impulsivity sub-scale; LKN - the number of recognized diagnostic categories on the inattention scale (i.e. observed often and very often in child's behavior) in ADHD Rating Scale; LKI - the number of recognized diagnostic categories on the hyperactivityimpulsivity scale (i.e. observed often and very often in child's behavior) in ADHD Rating Scale; = "not significant difference"; < and > "significant difference $(\mathrm{p}<0.05)$ "; *** - significant on $\mathrm{p}<0.001$ 
tial storage as well as in central executive components of working memory. This result suggests that verbal storage weakness is specific with language disorders but not with ADHD. Symptoms of inattention but not hyperactivity/impulsivity were associated with verbal and visual-spatial central component measures independent of language ability. It seems that working memory deficits was more strongly related to inattentive than to hyperactivity-impulsivity subtypes of ADHD.

The primary goal of the present study is to compare the functioning of the phonological loop and the central executive system in the situation of manipulation of verbal material in children with and without ADHD. A second objective of this study is to compare the functioning of each component of working memory in children with ADHD inattentive and mixed subtypes.

\section{Participants}

132 children with and without ADHD were examined. All the children in the ADHD group met the DSM-IVTR criteria of that disorder. Each child who met those criteria was further classified according to ADHD subtypes An assessment of the symptoms was made using:

- a clinical interview with the children's parents,

- two scales with wide diagnostic spectrum of Thomas M. Achenbach: Child Behavioural Checklist - CBCL (Achenbach, 1991) and Teacher's Report Form - TRF (Achenbach, 1991),

- ADHD Rating Scale (DuPaul et al., 1998),

- the Iowa-Conners (IOWA) Questionnaire for parents and teachers (DuPaul et al., 1998).

Children with the ADHD mixed subtype formed the first experimental group (mixed ADHD $n=64 ; 59$ boys and 5 girls), while the second group was made up of children with the ADHD inattentive subtype (inattentive ADHD $n=21 ; 17$ boys and 4 girls). The control group consisted of children without impairments (control $\mathrm{n}=47$, including 40 boys and 7 girls). All participants were 9-11 years old. The sample characteristics are shown in Table 1.

Group differences were tested with U Mann-Whitney test.

\section{Methods: evaluating of verbal working memory}

\section{The auditory serial addition task}

This task was developed specifically for this study. It demands simultaneous maintaining of the received information (numbers) in memory and performing mental operations (addition) on these data. Participants were asked to listen to a sequence of 30 numbers between 1 and 9, played from an audiotape. The numbers were presented in random fixed order at 4 second intervals. The task was to add the number currently heard to the one preceding it and to give the result of this 
operation. The task seems to be mathematically easy because the addenda never exceeded 9. Nevertheless, difficulties arose due to the necessity of maintaining the previously given and actually presented numbers (the active phonological loop), of performing addition of these numbers (the active central executive system) and, finally, of articulating the result. The material was presented by use of an audio tape to obtain similar conditions for the stimuli presentation (time intervals between numbers and the way of number demonstration). Because of this, it was not possible to wait for the child to produce a response. If the participant didn't do the task during four seconds, he could miss the actually added numbers and start in any moment after hearing the next number. Two types of incorrect answers could be registered. They were: addition mistakes (called "errors") and missing reactions, that is, passing over the addition of numbers. Additionally, the experimental material was divided into three parts: the first ten numbers, the second ten numbers, and the last ten numbers. The performance of these three parts was compared, which allowed observing potential changes in the dynamics of the cognitive processes. The following indexes of the performance were estimated:

1. number of missing reactions in the first part

2. number of missing reactions in the second part

3. number of missing reactions in the third part

4. total number of missing reactions

5. number of incorrect reactions in the first part

6. number of incorrect reactions in the second part

7. number of incorrect reactions in the third part

8. total number of incorrect reactions.

The serial subtraction from 100 by " $n$ " value without and with an external distractor

This task was intended to measure the storage of information, performing operations on stimuli and selective attention (Domańska, 2004). The task consisted of two parts. In the first part the classical version of a neuropsychological trial relying on subtraction of the "n" value from 100 was administered (Lezak, 1983; Strauss, Sherman, Spreen, 2006). On account of the age of participants (children from 9 years old) the " $n$ " value was three (the lower difficulty level). In the second part, the same task was performed, but in the presence of an external distractor which was auditory stimuli (a radio news program) played from a tape recorder. The instruction stated that participants shouldn't pay an attention to the content of the program. The primary aim of the second part of the task was to check if an auditory distractor had a significant adverse effect on the progress of subtraction. The indices of the performance of this task were:

1. The time of subtraction performance without the presence of the distractor

2. The time of subtraction performance in the presence of the distractor

3. The number of type I mistakes in both experimental situations

4. The number of type II mistakes in both experimental situations. 
Figure1. Average numbers of mistakes in three parts of the auditory serial addition task in separate groups

\begin{tabular}{|ll|}
\hline Missing reactions 1 & $\square$ Missing reactions 2 \\
$\square$ Missing reactions 3 & Q Total score of missing reactions \\
$\square$ Error 1 & QError 2 \\
目Error 3 & m Total score of errors \\
\hline
\end{tabular}

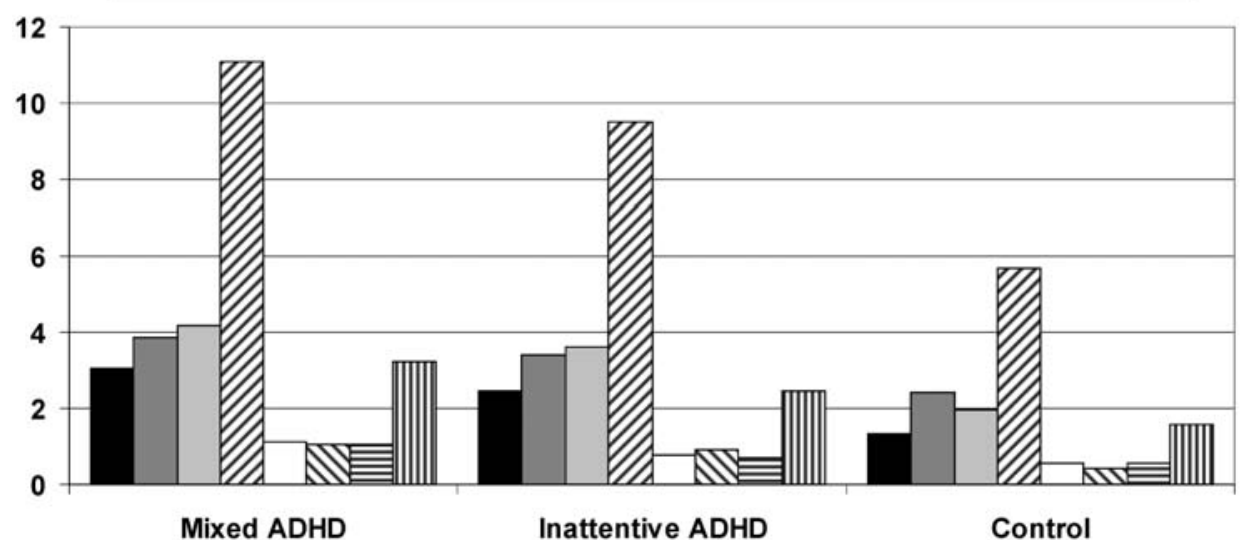

Missing reaction $1-$ number of missing reactions in the first part of the task Missing reaction 2- number of missing reactions in the second part of the task Missing reaction 3 - number of missing reactions in the third part of the task

Error 1 - number of incorrect reactions in the first part Error 2 - number of incorrect reactions in the second part Error 3 - number of incorrect reactions in the third part

The answers were considered as type I mistakes when participants made some small error in counting, i.e. the result given differed from the correct answer by 1 or 2 . When a child made a decade error, e.g. " $97,94,91,78,74,71,78,74,71 \ldots$ ". it was treated as a type II mistake. It was often the case that the values of digits were reported correctly, but the decade values were not.

\section{Results}

\section{The auditory serial addition task}

This task involves working memory processes, concentration on the task and divisibility of attention (allocation of resources needed for simultaneous performance of two mental tasks). Figure 1 presents average performance accuracy of all groups.

In mixed ADHD children, there was a tendency to increase the numbers of missing reactions with time, while no change was observed in the number of counting mistakes. Wilcoxon Matched-Paired Test showed that the number of 
Table 2. Differences in missing reactions and counting mistakes (errors) in the auditory serial addition task achieved by children from mixed ADHD, inattentive ADHD and control groups

\begin{tabular}{|c|c|c|c|c|c|c|c|}
\hline & \multicolumn{2}{|c|}{$\begin{array}{c}\text { Mixed } \\
\text { ADHD } \\
(\mathrm{N}=64) \\
\mathrm{a}\end{array}$} & \multicolumn{2}{|c|}{$\begin{array}{c}\text { Inattentive } \\
\text { ADHD } \\
(\mathrm{N}=21) \\
\mathrm{b}\end{array}$} & \multicolumn{2}{|c|}{$\begin{array}{l}\text { Control } \\
\text { group } \\
(\mathrm{N}=47) \\
\mathrm{c}\end{array}$} & \multirow[t]{2}{*}{$\begin{array}{l}\text { Pairwise } \\
\text { comparisons } \\
\text { (Mann-Whitney U) }\end{array}$} \\
\hline & M & SD & M & SD & $\mathrm{M}$ & SD & \\
\hline missing reactions 1 & 3.06 & 1.91 & 2.48 & 2.06 & 1.33 & 1.16 & $\mathrm{a}=\mathrm{b} ; \mathrm{a}>\mathrm{c} ; \mathrm{b}=\mathrm{c}$ \\
\hline missing reactions 2 & 3.87 & 1.92 & 3.42 & 1.74 & 2.42 & 1.90 & $a=b ; a>c ; b>c$ \\
\hline missing reactions 3 & 4.16 & 2.20 & 3.62 & 2.39 & 1.96 & 1.57 & $a=b ; a>c ; b>c$ \\
\hline $\begin{array}{l}\text { total score of missing } \\
\text { reactions }\end{array}$ & 11.09 & 5.18 & 9.52 & 5.15 & 5.69 & 3.95 & $\mathrm{a}=\mathrm{b} ; \mathrm{a}>\mathrm{c} ; \mathrm{b}>\mathrm{c}$ \\
\hline error 1 & 1.11 & 1.56 & 0.76 & 0.83 & 0.54 & 0.71 & $\mathrm{a}=\mathrm{b}=\mathrm{c}$ \\
\hline error 2 & 1.06 & 1.46 & 0.90 & 0.94 & 0.42 & 0.66 & $\mathrm{a}=\mathrm{b} ; \mathrm{a}>\mathrm{c} ; \mathrm{b}=\mathrm{c}$ \\
\hline error 3 & 1.04 & 1.51 & 0.71 & 0.64 & 0.58 & 0.90 & $\mathrm{a}=\mathrm{b}=\mathrm{c}$ \\
\hline total score of errors & 3.22 & 3.58 & 2.47 & 1.66 & 1.58 & 1.50 & $a=b ; a>c ; b>c$ \\
\hline
\end{tabular}

$=$ "non significant difference"

$<$ and $>$ "significant difference $(\mathrm{p}<0.05)$ "

missing reactions was significantly lower in the first part of the task than in the second $(Z=3.670, p<0.001)$ and in the third $(Z=3.377, p<0.001)$. The difference between the second and the third parts was not statistically significant $(Z=1.198, p>0.05)$. Differences in number of errors were not statistically significant.

A similar tendency was observed in inattentive ADHD children. The number of missing reactions was significantly lower in the first part than in the second part $(Z=1.917, p<0.05)$ and the third part $(Z=2.044, p<0.05)$ of the task. The difference between the second and third parts was not statistically significant $(Z=0.504, p>0.05)$. Differences in errors were not statistically significant.

In the control group, there were significantly fewer missing reactions in the first than in the second part $(Z=3.107, p<0.01)$. In the third part the number of missing reactions decreased in comparison with the second part (but the difference still was not significant $Z=1.505, p>0.05$ ). On the other hand, the difference between the first and third part was significant (in the third part higher than in first $Z=2.515, \mathrm{p}<0.05)$. The lower number of missing reactions in the third part (which was not significantly different from the number of mistakes in the second part) may be attributed to gaining skill in the task. Differences in performance on the simultaneous sum task between groups are presented in Table 2. 
Table 3. Reaction time and number of errors in both experimental conditions (with and without distractor) in all groups

\begin{tabular}{|c|c|c|c|c|c|c|c|}
\hline \multirow{2}{*}{ U) } & \multicolumn{2}{|c|}{$\begin{array}{c}\text { Mixed } \\
\text { ADHD } \\
(\mathrm{N}=64)\end{array}$} & \multicolumn{2}{|c|}{$\begin{array}{l}\text { Inattentive } \\
\text { ADHD } \\
(\mathrm{N}=21)\end{array}$} & \multicolumn{2}{|c|}{$\begin{array}{l}\text { Control } \\
\text { group } \\
(\mathrm{N}=47)\end{array}$} & \multirow[t]{2}{*}{$\begin{array}{l}\text { Pairwise } \\
\text { comparisons } \\
\text { (Mann -Whitney }\end{array}$} \\
\hline & M & SD & M & SD & M & SD & \\
\hline $\begin{array}{l}\text { Time } \\
\text { without distractor }\end{array}$ & 138.04 & 68.83 & 127.09 & 47.10 & 110.72 & 64.77 & $\mathrm{a}=\mathrm{b} ; \mathrm{a}>\mathrm{c} ; \mathrm{b}>\mathrm{c}$ \\
\hline $\begin{array}{l}\text { Time } \\
\text { with distractor }\end{array}$ & 145.53 & 81.03 & 149.95 & 103.70 & 95.78 & 44.28 & $\mathrm{a}=\mathrm{b} ; \mathrm{a}>\mathrm{c} ; \mathrm{b}>\mathrm{c}$ \\
\hline $\begin{array}{l}\text { Type I mistakes } \\
\text { without distractor }\end{array}$ & 4.21 & 5.71 & 3.52 & 4.41 & 2.45 & 3.03 & $\mathrm{a}=\mathrm{b}=\mathrm{c}$ \\
\hline $\begin{array}{l}\text { Type I mistakes } \\
\text { with distractor }\end{array}$ & 4.29 & 5.74 & 5.42 & 6.72 & 2.03 & 2.03 & $\mathrm{a}=\mathrm{b} ; \mathrm{a}>\mathrm{c} ; \mathrm{b}>\mathrm{c}$ \\
\hline $\begin{array}{l}\text { Type II mistakes } \\
\text { without distractor }\end{array}$ & 2.26 & 3.12 & 1.86 & 2.10 & 1.21 & 2.35 & $\mathrm{a}=\mathrm{b}=\mathrm{c}$ \\
\hline $\begin{array}{l}\text { Type II mistakes } \\
\text { with distractor }\end{array}$ & 3.73 & 3.88 & 2.62 & 3.29 & 0.87 & 2.10 & $\mathrm{a}=\mathrm{b} ; \mathrm{a}>\mathrm{c} ; \mathrm{b}>\mathrm{c}$ \\
\hline
\end{tabular}

$=$ "non significant difference"

$<$ and $>$ "significant difference $(\mathrm{p}<0.05)$ "

There were no statistically significant differences between the inattention type ADHD and mixed type ADHD in the simultaneous sum task. The number of missing reactions as well as the number of counting mistakes was similar.

In contrast, children from the control group showed significantly fewer missing reactions in each of the three parts of the task (missing reactions $1 \mathrm{Z}=4.189$, $\mathrm{p}<0.001$; missing reactions $2 \mathrm{Z}=3.013, \mathrm{p}<.01$; missing reactions $3 \mathrm{Z}=4.584$, $\mathrm{p}<0.001)$, and in total score of missing reactions $(Z=4.595, p<0.001)$, when compared with the mixed ADHD group. The analysis of numbers of counting mistakes revealed statistically significant differences only in the second part of task. This means that children without symptoms of ADHD made significantly fewer mistakes in the middle part of the task (error $2 \mathrm{Z}=2.114, \mathrm{p}<0.05$ ). The total number of mistakes also differed in these groups $(Z=2.602, p<0.01)$.

Children with the inattention type of ADHD differed from children without ADHD to a lesser degree than children with the mixed type of ADHD. There were significantly more missing reactions in the second part $(Z=2.200 \mathrm{p}<0.05)$, the third part of the task $(Z=2.661, p<0.01)$ and in the total score $(Z=2.368, p<0.05)$. Results of the first part of the task (number of missing reactions 1 ) did not reveal differences between these two groups. The total score of errors was significantly greater in the inattentive ADHD group than in the control, nevertheless there were no differences between these groups in the performance of separate parts of the task. 


\section{The serial subtraction from 100 by "n" value without and with an external distractor}

Results obtained by the children in this task should be investigated from two points of view: firstly, if differences between groups were shown, secondly, if effects of the external distractor were present among children in each group.

While type I mistakes can show attention disturbances, and in the case of small children also difficulties in counting, type II mistakes may be considered as the consequence of difficulties in concentration and in verbal working memory.

Analysis of time in completing the non-distractor condition showed significant between-group differences. The largest emerged between mixed ADHD and the control groups $(Z=2.618, p<0.01)$. Children from the control group also differed from the inattention ADHD group $(Z=1.996, \mathrm{p}<0.05)$. The two ADHD groups did not differ significantly $(Z=1.128, p>0.05)$. In the distractor condition, the differences between control and mixed ADHD groups $(Z=3.099, p<0.01)$ and between control and inattentive ADHD groups $(Z=2.581, p<0.01)$ were even greater. The two ADHD groups did not differ significantly.

The frequency of type I mistakes and type II mistakes in the non-distractor condition was similar in the three groups. In the distractor condition, the control group was significantly more accurate than the mixed ADHD group $(Z=3.939$, $\mathrm{p}<0.001)$ as well as the inattention ADHD group $(Z=1.996, p<0.05)$. The difference between the two ADHD groups was not significant $(Z=1.029$, $\mathrm{p}>0.05)$. The same pattern emerged when type I mistakes and type II mistakes were analyzed.

Overall, the results indicate that the ADHD children are slower than their typically developing peers. They are also less accurate, but only when they are required to carry out calculations in the presence of auditory distractors. Thus, the distractor's influence appeared to be very important. In order to explore this further, within-subject comparisons (using the Wilcoxon Test) were carried out between the distractor and non-distractor conditions, separately for each group.

The presence of distractors significantly increased the frequency of errors of the first type in the inattentive ADHD group $(Z=2.392, p<0.05)$. It had no significant effect on the mixed ADHD group $(Z=0.460, p>0.05)$. In contrast, the control group made significantly fewer mistakes in the distactor than no distractor condition $(Z=2.372, \mathrm{p}<0$.05) (see Table 4).

Errors of the second type were significantly more frequent in the distractor condition in the mixed ADHD group $(Z=2.856, p<0.01)$, but not in the inattentive ADHD group $(Z=1.111, p>0.05)$. In the control group, the errors were, again, less frequent in the distractor condition, though the difference was not significant $(Z=0.706, \mathrm{p}>0.05)$. 
Table 4. Comparison of performance "The serial subtraction from 100 by " $n$ " value without and with an external distractor" in mixed ADHD, inattentive ADHD and control groups (using Wilcoxon Matched-Pairs Test)

\begin{tabular}{lcccc}
\hline & & $\begin{array}{c}\text { Mixed ADH } \\
(\mathrm{N}=64)\end{array}$ & $\begin{array}{c}\text { Inattentive ADHD } \\
(\mathrm{N}=21)\end{array}$ & $\begin{array}{c}\text { Control group } \\
(\mathrm{N}=47)\end{array}$ \\
\hline Time & $\mathrm{Z}$ & 1.134 & 1.147 & 2.438 \\
& $\mathrm{P}$ & n.i. & n.i. & $0.014^{*}$ \\
Type I mistakes & $\mathrm{Z}$ & 0.460 & 2.392 & \\
& $\mathrm{P}$ & n.i. & $0.016^{*}$ & 2.372 \\
& & & & $0.017^{*}$ \\
Type II mistakes & $\mathrm{Z}$ & 2.856 & 1.111 & 0.706 \\
& $\mathrm{P}$ & $0.004^{* *}$ & n.i. & n.i. \\
\hline
\end{tabular}

* - significant on $\mathrm{p}<0.05$

** - significant on $\mathrm{p}<0.01$

n.i. - no significant differences

Finally, both ADHD groups were slightly (and non-significantly) slower in the presence of distractors (mixed ADHD: $Z=1.134, p>0.05$; inattentive ADHD: $Z=1.147, p>0.05)$, while the control group was significantly faster $(Z=2.438$, $\mathrm{p}<0.05)$.

\section{Discussion}

The present study was designed to evaluate the level of verbal working memory functioning in ADHD children. Disturbances in these cognitive functions can be considered as the typical feature of ADHD. Therefore their multidimensional description seemed to be very important. Finding the potential dysfunction caused by the neuronal basis of ADHD will be better understood. In this study two experimental tasks: "The simultaneous sum task" and "The subtraction with and without distractor task" were designed to assess verbal working memory.

The results obtained in "The simultaneous sum task" revealed no differences between mixed ADHD and inattentive ADHD groups. Diversity of symptoms in ADHD subtypes doesn't reflect diversity of difficulties in short but intensive concentration and working memory functioning. However, greater differences were observed between healthy children and children with mixed ADHD type than between healthy children and children with inattention ADHD type. These differences concerned the number of missing reactions. This means that children didn't remember numbers should be added. Thus, it may be considered not as a result of difficulties in the performance of the operation on verbal material (central executive system) but as a consequence of difficulties in material maintained in the 
phonological loop of verbal working memory. In comparison of the different aspects of working memory, the storage system seems to be more disturbed.

In "The simultaneous sum task" the concentration of attention can also be evaluated. Analysis of the dynamic of mistakes in the three parts of the task revealed that the quality of performance worsened with passage of time in the ADHD groups. This can be interpreted as a symptom of the worse state of attention. For comparison, in the control group the effect of better performance in the last part of the task was observed. These results can be explained by referring to difficulties in maintaining of attention in ADHD.

Verbal working memory was significantly involved in "The serial subtraction task" (the activity of the phonological loop consisting on storage the last number was spoken). Thus, the lack of differences in the number of mistakes between all groups shows that functioning of phonological loop is not disturbed if the level of task difficulty is not great. However, the longest time of performance the task in the group of mixed ADHD type could be interpreted as a consequence of impairments in the phonological loop. Using the external distractor raises task difficulty. It caused more significant differences in the number of mistakes between children with ADHD and healthy children. This may suggest that the loop functioning is not effective when selective attention is involved in the task. The presence of the external distractor caused difficulties in concentration on the task and in verbal working memory in children with mixed type of ADHD. It also caused impairments in concentration on the task and in mental processes (mathematical manipulations) in children with the inattention type of ADHD. The study revealed that healthy children were not susceptible to negative external factors. This fact was confirmed by faster progress of cognitive processes and the lower number of mathematical mistakes.

Additionally, the results of the study allow for making an attempt to conclude about the neuronal basis of disturbances showed by children with ADHD. Separate components involved in the storage and in the rehearsal of material are included in verbal memory independently of visual or auditory modality. The posterior parietal cortex (mainly in the left hemisphere) is involved in storage but the frontal region in rehearsal (mainly Broca's region, premotor cortex and SMA) (Baddley, 2003; Smith \& Jonides, 1997; Gruber \& Cramon, 2001; Martinussen \& Tannock, 2006). The dorsolateral prefrontal cortex is activated by the process of manipulating information, especially when information have been temporarily coded not only stored.

In the present study verbal working memory was evaluated. Results revealed a worse performance of tasks in ADHD children than in healthy children. On this basis conclusions can be drawn about impairments in the functioning of the posterior parietal cortex in the left hemisphere and in the dorsolateral prefrontal cortex.

The analysis of neuropsychological mechanisms has confirmed the hypothesis that the inattention type of ADHD diagnosed on the basis of DSM IV is "the 
weaker version" of the mixed type. This conclusion is consistent with prior research demonstrating that children with mixed and inattention types of ADHD have similar neuropsychological deficits and differences refer mainly to their severity (more severe in the mixed type).

\section{References}

Achenbach, T.M. (1991). Manual for the Child Behavior Checlist/4-18 and 1991 profile. Burlington: University of Vermont.

Achenbach, T.M. (1991). Manual for the Teacher's Report Form and 1991 profile. Burlington: University of Vermont.

Andres P. (2003). Frontal cortex as the central executive of working memory: time to revise our view. Cortex, 39, 871-895.

Baddeley, A. (2003). Working memory and language: an overview. Journal of Communication Disorders, 36, 189-208.

Barkley, R.A. (1997). Behavioral inhibition, sustained attention and executive functions: Constructing a unifying theory of ADHD. Psychological Bulletin, 121, 65-94.

Binder, M. (2001). Neuroobrazowanie pamięci roboczej (Neuroimaging studies on working menory). Studia Psychologiczne, 39, 1, 7-24.

Brocki, K.C., Nyberg, L., Thorell, L.B., \& Bohlin, G. (2007). Early concurrent and longitudinal symptoms of ADHD and ODD: relations to different types of inhibitory control and working memory. Journal of Child Psychology and Psychiatry, 48, 10, 1033-1041.

Castellanos, F.X., Tannock R (2002). Neuroscience of attention-deficit hyperactivity disorder: The search for endophenotypes. Nature Reviews Neuroscience, 3, 617-628.

Cohen, N.J., Vallance, D.D., Barwick, M., Im, N., Menna, R., Horodezky, N.B., \& Isaacson, L. (2000). The interface between ADHD and language impairment: An examination of language, achievement and cognitive processing. Journal of Child Psychology and Psychiatry, 41, 353-362.

Domańska, Ł. ( 2004). Więźniowie podzielonej przestrzeni. Zaburzenia uwagi w pomijaniu stronnym (The hostages of divided space. Attention deficits in unilateral neglect). Lublin: Wyd. UMCS.

DuPaul, G.J.,Power, T.J., Anastopoulos, A.D., \& Reid, R. (1998). ADHD Rating Scale - IV: Checklists, Norms, and Clinical Interpretation. New York: Guilford Press.

Gruber, O. \& von Cramon, D.Y. (2001). Domain-Specific distribution of working memory processes along human prefrontal and parietal cortices. Neuroimage, $13,6, \mathrm{~S} 679$.

Jodzio, K. (2008). Neuropsychologia intencjonalnego działania. Koncepcje funkcji wykonawczych (Neuropsychology of intentional behavior. Concepts of executive functions). Warszawa: Wydawnictwo Naukowe Scholar. 
Lezak, M. (red.) (1983). Neuropsychological Assessment. Oxford University Press. Martinussen, R. \& Tannock, R. (2006). Working memory impairments in children with attention-deficit hyperactivity disorder with and without comorbid language learning disorders. Journal of Clinical and Experimental Neuropsychology, 28, 1073-1094.

Smith, E.E. \& Jonides, J. (1997). Working memory: A view from Neuroimaging. Cognitive Psychology, 33, 5-42.

Strauss, E., Sherman, E.M.S., \& Spreen, O. (2006). A Compendium of Neuropsychological Tests: Administration, Norms, and Commentary. Oxford: Oxford University Press

Szatkowska, I. (2005). Udział podstawnej kory przedczołowej w pamięci operacyjnej (The partcipation of orbitofrontal cortex in working memory). Studia Psychologiczne, 43, 1, 29-36.

Vallar, G., Papagno, C. (2002). Neuropsychological impairments of verbal shortterm memory. In A.D. Baddeley, M.D. Kopelman \& B.A. Wilson (Eds.), Handbook of memory disorders ( $\mathrm{pp}$ 249-270). Chichester: Wiley.

Van Rooy, C., Stough, C., Pipingas, A., Hocking, C., \& Silberstein, R.B. (2001). Spatial working memory and intelligence. Biological correlates. Intelligence, $29,275-292$.

Westerberg, H., Formssberg, H., \& Klingberg, T. (2001). fMRI and psychometrics of visuo-spatial working memory in children with and without ADHD. Neuroimage, 13, 6, 761.

Wu, K.K., Anderson, V., \& Castiello, U., (2002). Neuropsychological evaluation of deficits in executive functioning for ADHD children with or without LD. Developmental Neuropsychology, 22, 501-531.

Wu, K.K., Andersen, V., \& Castiello, U. (2006). Attention-deficit/hyperactivity disorder and working memory: A task switching paradigm. Journal of Clinical and Experimental Neuropsychology, 28, 8, 1288-1306. 